\title{
Prevalence of and risk factors for stent migration-induced duodenal perforation
}

\section{다 $($ ) $\odot$}

\author{
Authors \\ Pauline M.C. Stassen, David M. de Jong, Jan-Werner Poley, Marco J. Bruno ${ }^{1}$, Pieter J.F. de Jonge
}

Institution

Department of Gastroenterology and Hepatology, Erasmus

MC University Medical Center Rotterdam, Rotterdam, The

Netherlands

submitted 7.8.2020

accepted after revision 19.11 .2020

\section{Bibliography}

Endoscopy International Open 2021; 09: E461-E469

DOI 10.1055/a-1337-2321

ISSN 2364-3722

(C) 2021. The Author(s).

This is an open access article published by Thieme under the terms of the Creative Commons Attribution-NonDerivative-NonCommercial License, permitting copying and reproduction so long as the original work is given appropriate credit. Contents may not be used for commecial purposes, or adapted, remixed, transformed or built upon. (https://creativecommons.org/licenses/by-nc-nd/4.0/)

Georg Thieme Verlag KG, Rüdigerstraße 14,

70469 Stuttgart, Germany

Corresponding author

P.M.C. Stassen, MD, Erasmus MC University Medical

Center Rotterdam, Department of Gastroenterology and Hepatology, Postbox 2040, 3000 CA Rotterdam,

The Netherlands

Fax: +31 107030331

p.stassen@erasmusmc.nl

\section{ABSTRACT}

Background and study aims The safety of transpapillary biliary drainage by stent placement through endoscopic retrograde cholangiography (ERC) may be compromised by the occurrence of stent migration-induced perforation of the duodenal wall (SMDP). We aimed to assess the prevalence rate, risk factors and clinical course of SMDP.

Patients and methods This retrospective cohort study included all patients who underwent an ERC with biliary plastic stent placement, between January 2014 and December 2018. Patients with an SMDP were identified from our endoscopy complication registry.

Results 1227 patients underwent an ERC, of whom 629 patients (51\%) with biliary plastic stent placement; in 304 patients $(25 \%)$ stents were placed for perihilar strictures. Thirteen patients with SMDP were identified. The prevalence was $2.1 \%$ for patients with biliary plastic stent placement and $4.3 \%$ for patients stented for a perihilar stricture. All SMDPs occurred in patients with a perihilar stricture and with stents $\geq 12 \mathrm{~cm}$ (range $12-20 \mathrm{~cm}$ ). Another potential risk factor was stent insertion into the left liver lobe, which was present in 10 of 13 patients. In 10 of 13 patients, SMDP was clinically suspected. Three of 13 patients were asymptomatic and diagnosed at elective stent retrieval. Eight patients could be endoscopically treated with an over-thescope clip. Four patients died due to abdominal sepsis despite repeated interventions.

Conclusion SMDP is a rare but potentially life-threatening complication of ERC after transpapillary drainage for perihilar biliary strictures. Stents $\geq 12 \mathrm{~cm}$ and stent insertion into the left liver lobe may be associated risk factors.

\section{Introduction}

Transpapillary biliary drainage with stent placement through endoscopic retrograde cholangiography (ERC) is a well-established treatment for bile duct obstruction due to either malignant or benign strictures or cholelithiasis. Improving biliary drainage by stent placement allows for symptom relief of jaundice, pruritus and pain, and improvement of liver function tests $[1,2]$.
Endoscopic placement of biliary stents may be complicated by stent occlusion, potentially leading to cholangitis, often necessitating repeat ERC. In addition, plastic stent migration is regularly encountered, with reported rates between $5 \%$ and $10 \%$ and a trend towards higher migration rates after sphincterotomy $[1,3]$. Fortunately, the majority of distally migrated stents pass the digestive tract uneventfully.

However, distal stent migration may lead to duodenal erosion or superficial ulcers caused by the mechanical friction between the tip of the stent and the opposite duodenal wall, pos- 
sibly increasing the risk of bleeding. Furthermore, pressure necrosis can eventually lead to perforation of the duodenal wall, as has been reported in case reports [4-30]. Although stent migration-induced perforation of the duodenal wall (SMDP) is considered a rare complication, it is associated with serious life-threatening complications including intra-abdominal or retroperitoneal abscesses, fistulation or sepsis $[1,10,31]$. Once perforation has occurred, early diagnosis and management including endoscopic or surgical closure of the defect are essential. Clinical presentation can be non-specific with symptoms that mimic those of cholecystitis or pancreatitis thereby obscuring early detection. As a result, a high index of suspicion is needed to diagnose this complication.

So far, SMDP has only been reported in case reports. The actual prevalence of this complication and associated risk factors are unknown. The current study aims to analyze the prevalence rate, clinical course and risk factors of SMDP in a tertiary referral center for pancreaticobiliary diseases.

\section{Patients and methods}

\section{Study design and study population}

A single-center retrospective cohort study was performed in our tertiary referral center. Firstly, all consecutive patients who underwent an ERC at our institution between January 2014 and December 2017, were identified from an endoscopy database (Endobase ${ }^{\circledR}$ ), in which all endoscopic procedures and reports are prospectively registered. All patients who underwent an ERC with biliary plastic stent placement were included for analysis. Secondly, all patients who were diagnosed with an SMDP between January 2014 and December 2018, were identified from our endoscopy complication registry. This complication registry is maintained prospectively and updated weekly. To be able to identify all patients who were diagnosed with an SMDP that was caused by stents placed in the study period (January 2014 - December 2017), we included patients diagnosed with an SMDP until December 2018, assuming that an SMDP would occur within 1 year after stent placement. An SMDP was defined as a duodenal wall perforation diagnosed by endoscopy and/or computed tomography (CT) scan, with or without clinical symptoms of abdominal pain, fever and elevated infection parameters. Of note, all patients undergoing an ERC with plastic stent placement for a hilar stricture at our institution, receive one gift of antibiotic prophylaxis pre-procedurally followed by 3 days of oral antibiotics post-procedurally.

This study was conducted according to the guidelines in the Helsinki Declaration and was approved by the ethics committee of the Erasmus MC University Medical Center Rotterdam, Rotterdam, the Netherlands.

\section{Selection criteria for plastic stent insertion}

The general approach to optimizing endoscopic drainage in operable patients with perihilar strictures was to initially drain the future liver remnant (decided after a multidisciplinary meeting involving surgeons, radiologists and oncologists). In inoperable patients, maximum drainage was attempted while taking care to avoid opacifying and draining atrophied segments. The ini- tial approach was to drain with plastic stents and exchange these for uncovered self-expandable metal stents (SEMS) after adequate drainage (based on bilirubin levels) was achieved. In all patients drainage of opacified segments was actively pursued, regardless of the initial drainage plan.

Initially center bend type stents were used, but after recognizing cases of duodenal perforation we switched to duodenal bend type stents. The use of plastic stents with a distal pigtail was considered, but due to pushability concerns in complex hilar strictures these stents have not been used in our institution.

The anatomy of patients with hilar strictures was based on both pre-operative imaging (mainly MRI/MRCP) and the cholangiogram obtained at endoscopic retrograde cholangiopancreatography (ERCP). Transpapillary stents were used and length and diameter (either 7 or 10 French) selection were based on anatomy and expected difficulty of multiple stent placement. The use of balloon dilation of the stricture was at the discretion of the endoscopist.

\section{Data collection}

With the use of a dedicated electronic endoscopic reporting system (Endobase) and the electronic hospital information system (HiX 6.1 HF103, ChipSoft B.V.), the following data were retrieved for all patients who underwent an ERC with plastic stent placement: demographic factors, medical history, indication of stent placement, etiology and location of the stricture, stricture dilatation before stent placement, performance of a sphincterotomy, and stent characteristics (i.e. number of inserted stents, type and bend (center or duodenal), location of the proximal tip of the stent and stent length and diameter). Furthermore, for all patients diagnosed with an SMDP, data were collected regarding clinical symptoms at presentation, date of diagnosis, treatment and outcome.

\section{Study outcomes}

The primary outcome was defined as the rate of SMDP in patients who underwent an ERC with plastic stent placement. Secondary outcomes were potential risk factors for SMDP, either disease-related or stent-related, and the treatment and clinical course of patients diagnosed with an SMDP.

\section{Statistical analysis}

Descriptive statistics were used to analyze the data. Continuous variables were described using mean and standard deviation (SD) for normally distributed variables or using median and range for non-normally distributed variables. Categorical variables were described using frequencies and percentages (\%). A univariate logistic regression analysis was performed to identify potential risk factors. Factors included in this analysis were disease-related and stent-related factors. For stricture-related factors (i.e. etiology of the stricture and stricture dilatation prior to stent placement), only biliary ERC procedures in which a plastic stent was placed for a stricture were included for analysis. For all other factors, all biliary ERCs with plastic stent placement were included for analysis. The statistical analyses were performed using the statistical software package IBM SPSS version 25. 


\section{Results}

\section{Prevalence rate and risk factors for SMDP}

Between January 2014 and December 2017, in 1227 patients (mean age 61 years (SD \pm 15.9 years), 54\% male) a total of 2486 ERCs were performed. In 51\% (629/1227) one or more biliary plastic stents were placed, encompassing a total of 1203 procedures. In 25\% (304/1227) one or more biliary plastic stents were placed for a perihilar stenosis. Baseline characteristics of the patients undergoing an ERC with plastic stent placement are shown in $>$ Table $\mathbf{1}$.

During the study period, 13 patients were diagnosed with an SMDP. Baseline patient characteristics are shown in $>$ Table 2. The prevalence rate of SMDP for all biliary ERC procedures with plastic stent placement was $1.1 \%(13 / 1203)$ and $1.9 \%(13 / 701)$ for the procedures with plastic stent placement for a perihilar stricture. The prevalence rate of SMDP for all patients undergoing a biliary ERC with plastic stent placement was $2.1 \%$ (13/ $629)$ and $4.3 \%(13 / 304)$ for the patients with plastic stent placement for a perihilar stricture. Importantly, all patients who were diagnosed with an SMDP had a perihilar stricture. SMDP did not occur in patients in whom a stent was placed for a distal stricture or for other indications than a stricture. The stricture was malignant in $62 \%(8 / 13)$ and benign in 39\% (5/ 13). In $54 \%$ (7/13) the stricture was dilated prior to stent placement. In $77 \%$ (10/13) a sphincterotomy was performed. In $54 \%$ (7/13) SMDP occurred after the first ERC with plastic stent placement. All ERCs were performed by or under direct supervision of endoscopists who are experienced in ERC. About half of patients with an SMDP had one stent in situ (54\% (7/13)). Median stent length was $15 \mathrm{~cm}$ (range 12-20) and median stent diameter was 10 French (range 7-10). SMDP occurred with both duodenal bend and center bend type stents (54\% (7/13) versus $46 \%(6 / 13)$, respectively). All stents were straight stents with a flap, from either Boston Scientific Inc. or Cook Medical Inc. No stents with a distal pigtail part were used. The location of the proximal tip of the stent was intrahepatic left in $77 \%(10 / 13)$, intrahepatic right in $15 \%(2 / 13)$ and in $8 \%(1 / 13)$ multiple stents were placed bilateral.

In $>$ Table 3 the results of the univariate logistic regression analysis are shown. The location of the stricture was not included in the univariate logistic regression analysis since SMDP only occurred in perihilar strictures. At univariate logistic regression, a stent placed to drain the left liver lobe and longer stent length were found to be associated with SMDP. Due to the relatively low number of SMDPs a multivariate logistic regression analysis could not be performed.

\section{Clinical course of SMDP}

$77 \%$ (10/13) were clinically suspected of SMDP based on their presentation with abdominal pain, fever and/or increased serum levels of inflammatory parameters. The remaining $23 \%$ (3/13) was asymptomatic and SMDP was diagnosed at elective stent retrieval. $80 \%(8 / 10)$ of the symptomatic patients presented within 14 days after ERC with stent placement. The medi-
- Table 1 Baseline characteristics of patients who underwent an ERC with plastic stent placement.

\begin{tabular}{|c|c|}
\hline Characteristic & $(n=629)$ \\
\hline Age $($ mean $\pm S D)$ & $59.8(15.0)$ \\
\hline Gender (\% male) & 61.0 \\
\hline \multicolumn{2}{|l|}{ Indication for plastic stent placement (\%) } \\
\hline - Obstructive jaundice & 50.7 \\
\hline - Cholangitis & 18.9 \\
\hline - Bile leakage & 11.8 \\
\hline - Drainage of gallstones & 10.7 \\
\hline $\begin{array}{l}\text { - Other (i.e bile duct obstruction without liver test } \\
\text { abnormalities, abdominal pain, duodenobiliary } \\
\text { reflux) }\end{array}$ & 8.0 \\
\hline Median number of ERCPs per patient (range) & $1(1-14)$ \\
\hline Sphincterotomy prior to stent placement (\%) & 73.1 \\
\hline \multicolumn{2}{|l|}{ Stenosis (\%) } \\
\hline - No stenosis & 20.7 \\
\hline - Distal stenosis & 31.0 \\
\hline - Perihilar stenosis & 48.3 \\
\hline - Dilatation prior to stent placement (\%) & 19.6 \\
\hline \multicolumn{2}{|l|}{ Number of stents in total in situ (\%) } \\
\hline$\cdot 1$ & 74.9 \\
\hline .2 & 21.6 \\
\hline .3 & 3.0 \\
\hline .5 & 0.2 \\
\hline .7 & 0.3 \\
\hline
\end{tabular}

ERC, endoscopic retrograde cholangiography; ERCP, endoscopic retrograde cholangiopancreatography.

an time between stent placement and diagnosis was 12 days (range 2-229).

The diagnosis was established by means of endoscopy alone in $39 \%(5 / 13)$ and in the remaining $39 \%(5 / 13)$ by CT scan. In $31 \%(4 / 13)$ the perforation was considered to be a contained perforation and could therefore be treated conservatively with only stent removal. These patients did not develop any complications nor needed additional interventions. In $62 \%$ (8/13) the perforation could be closed with an over-the-scope clip (OTSC) and $8 \%(1 / 13)$ had to undergo surgery since the perforation was too large to be successfully treated by endoscopic means. In total, $77 \%$ (10/13) received prophylactic antibiotics to prevent infection. Nevertheless, $38 \%$ (5/13) developed intra-abdominal or retroperitoneal abscesses for which they underwent percutaneous drainage. In $8 \%(1 / 13)$ a percutaneous transhepatic cholangiography (PTC) drain was placed. Endoscopic nasobiliary drainage was not routinely performed in our patients. In $15 \%$ (2/13) a right hemicolectomy needed to be performed. In the first patient, the stent was perforated through the hori- 
- Table 2 Baseline characteristics of patients diagnosed with SMDP.

\begin{tabular}{|c|c|}
\hline Characteristic & $(n=13)$ \\
\hline Age (mean \pm SD) & $62.3(14.1)$ \\
\hline Gender (\% male) & $10(76.9)$ \\
\hline \multicolumn{2}{|l|}{ Indication for plastic stent placement (\%) } \\
\hline - Obstructive jaundice & $8(61.5)$ \\
\hline - Cholangitis & $5(38.5)$ \\
\hline PSC (\%) & $2(15.4)$ \\
\hline \multicolumn{2}{|l|}{ Etiology (\%) } \\
\hline - Malignant & $8(61.5)$ \\
\hline - Benign & $5(38.5)$ \\
\hline \multicolumn{2}{|l|}{ Stricture location (\%) } \\
\hline - Distal & $0(0)$ \\
\hline - Perihilar & $13(100)$ \\
\hline - No stricture & $0(0)$ \\
\hline $\begin{array}{l}\text { Stricture dilatation prior to stent placement } \\
(\%)\end{array}$ & $7(53.8)$ \\
\hline Sphincterotomy prior to stent placement (\%) & $10(76.9)$ \\
\hline \multicolumn{2}{|l|}{ Number of stents in situ (\%) } \\
\hline . 1 & $7(53.8)$ \\
\hline .2 & $4(30.8)$ \\
\hline .3 & $1(7.7)$ \\
\hline - 4 & $1(7.7)$ \\
\hline Stent length (median (range)) & $15 \mathrm{~cm}$ (range $12-20$ ) \\
\hline Stent diameter (median (range)) & $\begin{array}{l}10 \text { French } \\
\text { (range } 7-10 \text { ) }\end{array}$ \\
\hline Bend stent (\% duodenal) & $7(53.8)$ \\
\hline \multicolumn{2}{|l|}{ Proximal tip of the stent (\%) } \\
\hline - Intrahepatic left & $10(76.9)$ \\
\hline - Intrahepatic right & $2(15.4)$ \\
\hline - Both & $1(7.7)$ \\
\hline
\end{tabular}

zontal part of the duodenum and the tip of the stent had caused a false aneurysm of the ileocolic artery. The ileocolic artery had to be coiled which led to an ischemic caecum. In the second patient, a submucosal hematoma in the wall of the caecum together with an ischemic caecum was found during surgery. This was probably caused by a fistula between the duodenum and the mesocolon of the colon ascendens, which had developed after the stent perforated the duodenal wall with extensive retroperitoneal infiltration.

Finally, 31\% (4/13) died due to ongoing abdominal sepsis, despite repeated endoscopic, percutaneous and/or surgical interventions. Two of these patients were diagnosed with an irre-
- Table 3 Univariate logistic regression analysis of patient-, strictureand stent characteristics in relation to SMDP.

\begin{tabular}{|l|l|l|}
\hline Characteristic & OR (95\% Cl) & $P$ value \\
\hline Age & $1.020(0.980-1.062)$ & 0.322 \\
\hline Male gender & $0.550(0.151-2.009)$ & 0.366 \\
\hline PSC & $1.421(0.312-6.479)$ & 0.650 \\
\hline $\begin{array}{l}\text { Etiology of the stricture - } \\
\text { malignant }\end{array}$ & $1.900(0.634-5.697)$ & 0.252 \\
\hline $\begin{array}{l}\text { Etiology of the stricture - } \\
\text { benign }\end{array}$ & $0.569(0.185-1.751)$ & 0.325 \\
\hline $\begin{array}{l}\text { Etiology of the stricture - } \\
\text { indeterminate }\end{array}$ & $0.784(0.101-6.094)$ & 0.816 \\
\hline $\begin{array}{l}\text { Stricture dilatation prior to } \\
\text { stent placement }\end{array}$ & $2.880(0.960-8.644)$ & 0.059 \\
\hline $\begin{array}{l}\text { Sphincterotomy prior to stent } \\
\text { placement }\end{array}$ & $0.782(0.214-2.866)$ & 0.711 \\
\hline
\end{tabular}

Number of stents in situ

\begin{tabular}{|l|l|l|}
\hline $\mathbf{1}$ & 1 & \\
\hline $\mathbf{2}$ & $1.530(0.457-5.122)$ & 0.490 \\
\hline $\mathbf{2}$ & $0.951(0.118-7.677)$ & 0.962 \\
\hline Stent diameter & $0.863(0.567-1.312)$ & 0.489 \\
\hline Stent length & $1.329(1.142-1.546)$ & $0.000^{1}$ \\
\hline $\begin{array}{l}\text { Proximal tip of the stent }- \\
\text { intrahepatic left }\end{array}$ & $14.064(3.840-51.516)$ & $0.000^{1}$ \\
\hline $\begin{array}{l}\text { Proximal tip of the stent - } \\
\text { intrahepatic right }\end{array}$ & $0.994(0.219-4.522)$ & 0.994 \\
\hline $\begin{array}{l}\text { Proximal tip of the stent }- \\
\text { bilateral intrahepatic }\end{array}$ & $0.552(0.071-4.277)$ & 0.570 \\
\hline
\end{tabular}

SMDP, stent migration-induced duodenal perforation; PSC, primary sclerosing cholangitis.

${ }^{1}$ Factors significantly associated with SMDP at univariate logistic regression analysis $(P<0.05)$.

sectable malignant hilar stricture and were unfit for surgery, and one elderly patient with a benign hilar stricture refused further surgical treatment after failure of endoscopic and percutaneous drainage, and wished to be discharged with palliative care at home. An overview of the clinical course of SMDP patients is shown in $>$ Table 4.

- Fig. 1 and > Fig. 2 show a biliary plastic stent which is perforated through the duodenal wall on fluoroscopy during ERC and on CT scan. Fig. 3 shows the endoscopic view of a perforated biliary plastic stent through the duodenal wall and $\mathbf{D}$ Fig. 4 shows an OTSC that has been placed over the perforation. - Fig. 5 shows fluoroscopy during ERC showing no contrast leakage after the plastic stent has been removed from the duodenal wall (contained SMDP). 
- Table 4 Clinical presentation, diagnosis and treatment of patients with SMDP.

\begin{tabular}{|c|c|c|c|c|c|c|}
\hline Case & Clinical presentation & $\begin{array}{l}\text { Days } \\
\text { after } \\
\text { ERCP }\end{array}$ & Diagnosis & $\begin{array}{l}\text { Treatment } \\
\text { perforation }\end{array}$ & Additional treatment & Outcome \\
\hline 1 & Abdominal pain & 2 & Endoscopy + CT & OTSC & $\begin{array}{l}\text { Antibiotics, drainage intra-abdomi- } \\
\text { nal and retroperitoneal abscesses }\end{array}$ & Recovered \\
\hline 2 & Abdominal pain, fever & 3 & Endoscopy & OTSC & $\begin{array}{l}\text { Antibiotics, drainage retroperito- } \\
\text { neal abscess }\end{array}$ & Recovered \\
\hline 3 & Abdominal pain, sepsis & 3 & Endoscopy + CT & OTSC & Antibiotics & Deceased \\
\hline 4 & Abdominal pain & 4 & Endoscopy + CT & OTSC & $\begin{array}{l}\text { Antibiotics, drainage intra-abdomi- } \\
\text { nal abscesses }\end{array}$ & Deceased \\
\hline 5 & Abdominal pain, fever & 4 & Endoscopy & OTSC & Antibiotics & Recovered \\
\hline 6 & Abdominal pain & 6 & Endoscopy & OTSC & Antibiotics & Recovered \\
\hline 7 & Complicated cholecystitis & 12 & Endoscopy $+\mathrm{CT}$ & Surgery & $\begin{array}{l}\text { Antibiotics, drainage retroperito- } \\
\text { neal abscess, right hemicolectomy }\end{array}$ & Deceased \\
\hline 8 & Abdominal pain, leukocytosis & 13 & Endoscopy & OTSC & $\begin{array}{l}\text { Antibiotics, drainage intra-abdomi- } \\
\text { nal and retroperitoneal abscesses }\end{array}$ & Deceased \\
\hline 9 & Asymptomatic & 22 & Endoscopy & Conservative & - & Recovered \\
\hline 10 & Fever, hematemesis & 26 & Endoscopy $+C T$ & OTSC & Antibiotics, right hemicolectomy & Recovered \\
\hline 11 & Asymptomatic & 125 & Endoscopy & Conservative & - & Recovered \\
\hline 12 & Asymptomatic & 126 & Endoscopy & Conservative & Antibiotics & Recovered \\
\hline 13 & Fever and cholestasis & 229 & Endoscopy & Conservative & - & Recovered \\
\hline
\end{tabular}

SMDP, stent migration-induced duodenal perforation; OTSC, over-the-scope clip; CT, computed tomography.

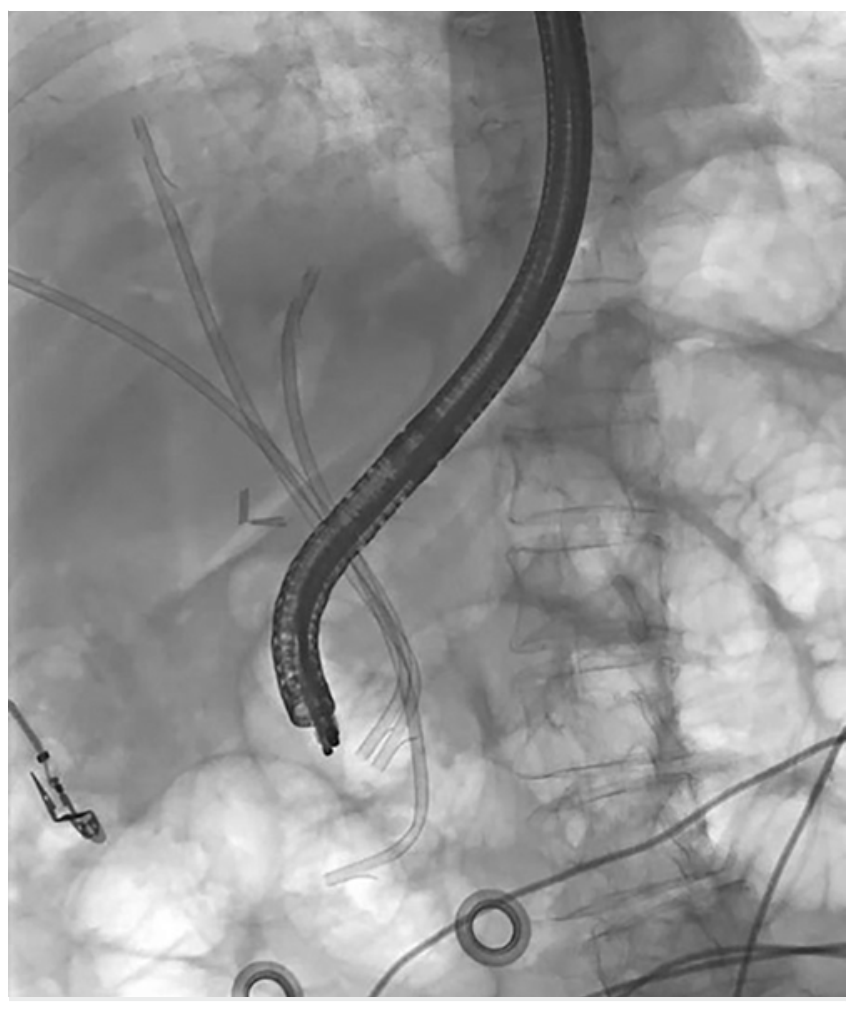

- Fig. 1 Fluoroscopy during ERC showing a biliary plastic stent perforated through the duodenal wall.

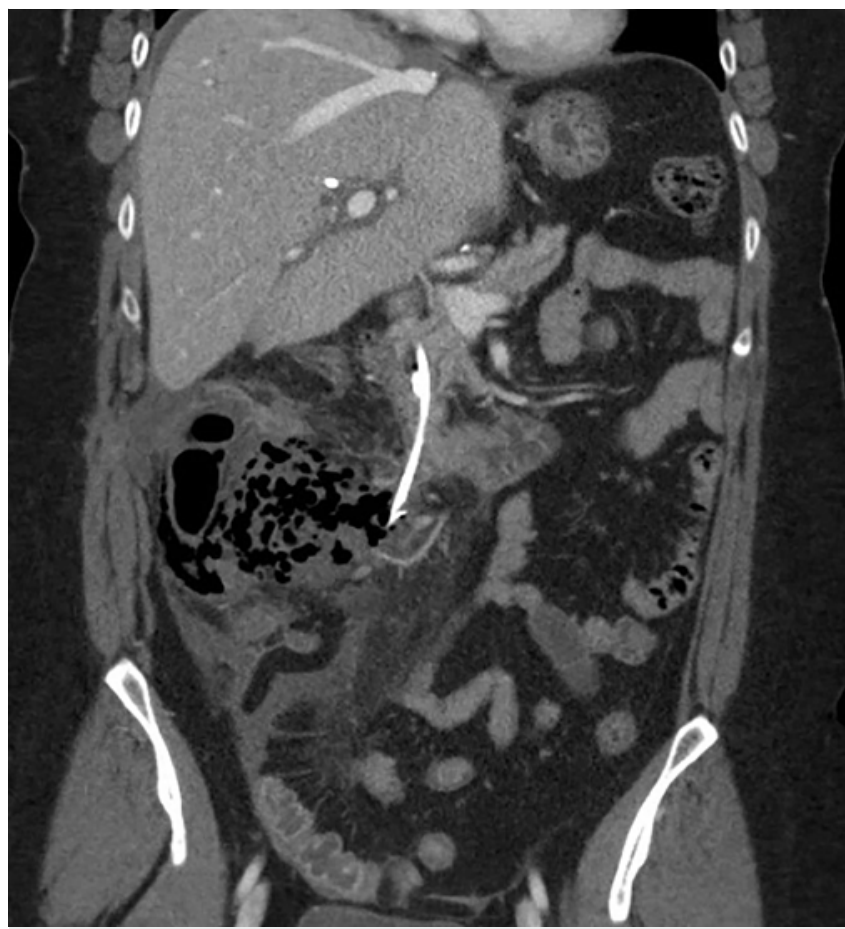

Fig. 2 CT scan showing a biliary plastic stent perforated through the duodenal wall. 


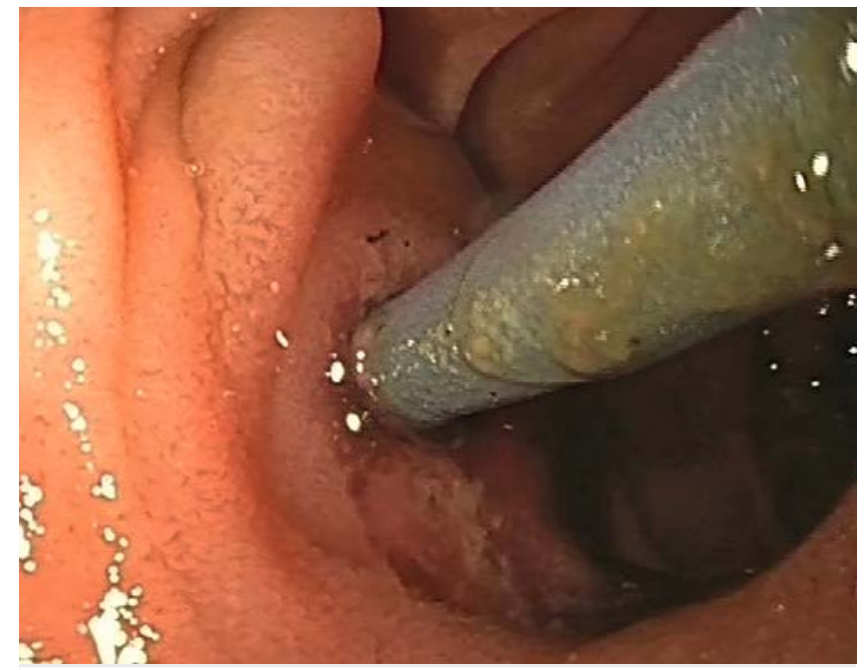

- Fig. 3 Endoscopic view of a perforated biliary plastic stent through the duodenal wall.

\section{Discussion}

Stent migration-induced perforation of the duodenal wall (SMDP) is a potentially life-threatening complication of ERC. In this study, we observed an overall SMDP prevalence rate of $1.1 \%$ in all biliary ERC procedures with plastic stent placement that were performed and a prevalence rate of $2.1 \%$ in patients after ERC with plastic stent placement. The prevalence rate in patients with stent placement for a perihilar stricture was as high as $4.3 \%$. According to this study, the most common clinical presentation of SMDP consists of sepsis with signs of peritonism within two to four weeks after ERC for a perihilar stricture with placement of a plastic stent $\geq 12 \mathrm{~cm}$ length. In all but one patient, the perforation site could be technically successfully closed endoscopically. Nevertheless, despite endoscopic closure in combination with antibiotic therapy, $60 \%$ of patients required additional abscess drainage or surgery to treat the septic complications, and the overall mortality of SMDP was $30 \%$.

To the best of our knowledge, this is the first study to report on the actual prevalence rate of SMDP in a large consecutive cohort of patients that undergo ERC. Previous publications only comprise case reports [4-30]. Prevalence rates in our study may seem high, however, SMDP may well be an underreported complication, due to hesitation of physicians to report a complication that may be (falsely) attributed to inadequate technical skills. The results of our study show that SMDP indeed is erroneously considered a rare complication of ERC and occurs also in expert ERC centers when experienced endoscopists performed the procedure. Our results provide for the first time a plausible estimate of the actual complication rate of SMDP. Since the risk of SMDP in our study for patients with a perihilar stricture is of the same magnitude as the risk of post-ERCP pancreatitis (3.5\%-9.7\%) and bleeding (0.3\%-9.6\%) [32], we propose to include the risk of SMDP in the informed consent procedure for patients undergoing an ERC for a perihilar stricture.

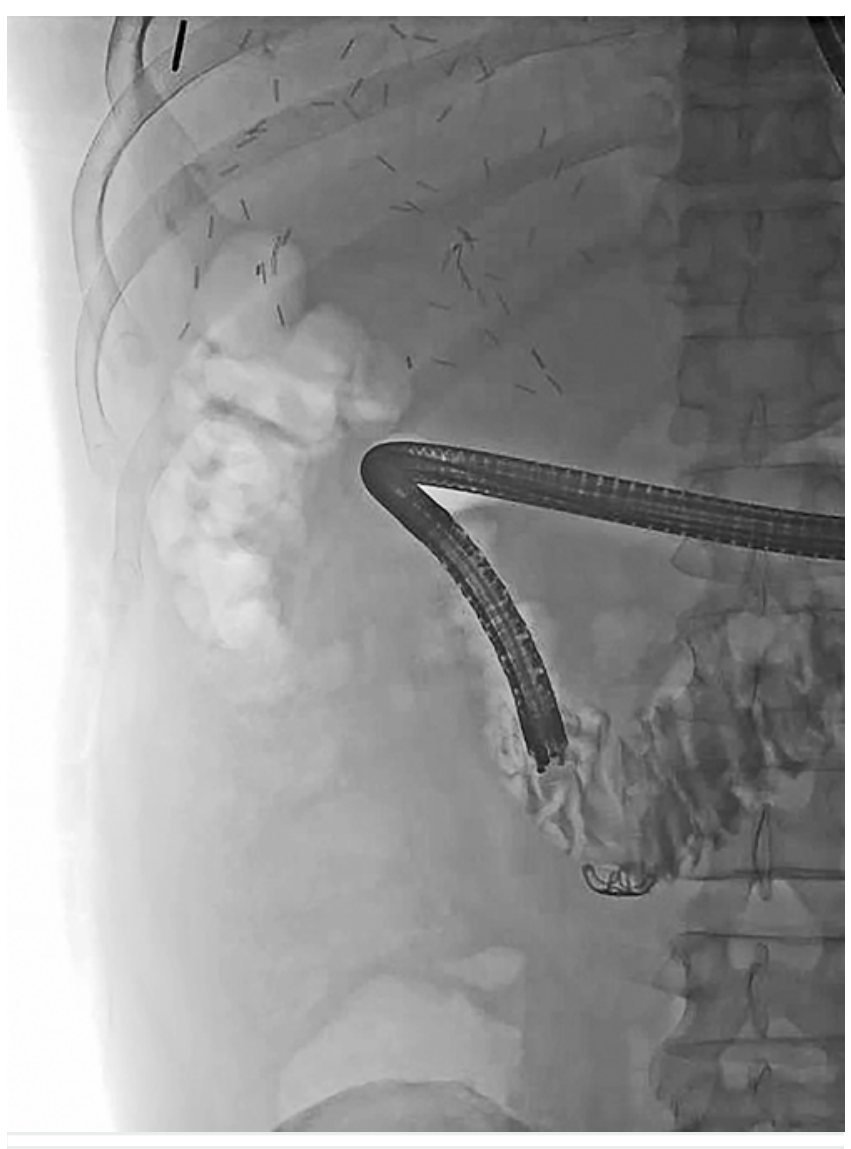

Fig. 4 Fluoroscopy during ERC showing no contrast leakage after placement of the OTSC.

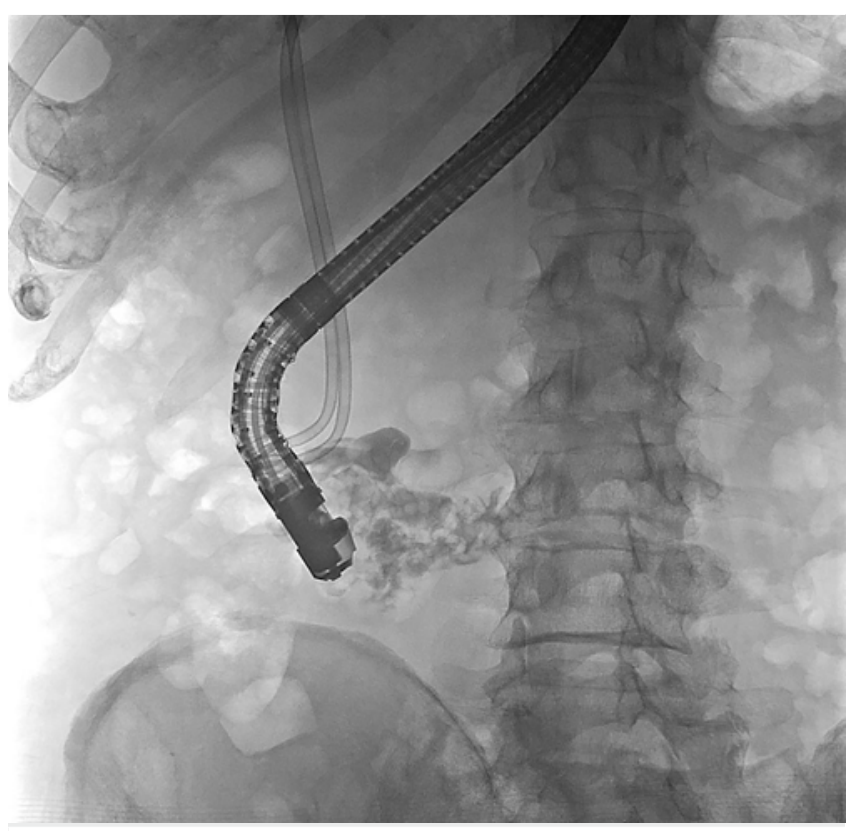

- Fig. 5 Fluoroscopy during ERC showing no contrast leakage after the plastic stent has been removed from the duodenal wall (contained SMDP). 
Considering the potential lethality of SMDP, prompt diagnosis and immediate treatment are of paramount importance. In our study, the majority of the patients presented with abdominal pain and sepsis within two to four weeks after placement of a plastic stent. This is in line with previously published case reports $[4,5,8,9,17,19,22-26,28-30]$. Symptoms of SMDP may mimic common complications of ERC, such as post-ERCP pancreatitis, cholangitis or cholecystitis. A high index of suspicion of the possibility of SMDP in patients with such symptoms is therefore warranted and the diagnostic workup often requires cross-sectional imaging. With regard to treatment, literature data are scarce. Although all symptomatic patients in our series were treated endoscopically within 24 hours after presentation, a large proportion developed abscesses despite prophylactic antibiotics. A strategy of primary surgical closure of the duodenal wall defect combined with peritoneal lavage might accelerate clinical course and improve outcome, and may be considered an adequate alternative in patients fit for surgery. In our series, four patients died due to ongoing intra-abdominal sepsis or respiratory failure. Surgical intervention was considered in all patients in case of failure of endoscopic therapy and/or persisting abdominal infection. Only one of these patients underwent surgery. It could be discussed whether this should have been performed in the remaining three patients that have deceased. However, two of them were diagnosed with progressive metastasized disease and were unfit for invasive treatment shortly after the SMDP was diagnosed. The remaining patient was diagnosed with a benign hilar stricture, but refused further surgical treatment after failure of endoscopic and percutaneous drainage and chose for palliative care at home. Our reported mortality rate may be influenced by the thigh prevalence of comorbidities in this group of patients.

It is difficult to compare our rate to what has been reported previously, as most published data on SMDPs predominantly come from case reports. We have only found two reports that described patients that deceased after an SMDP $[16,24]$. In the first report this concerned a patient with benign disease who was immediately treated surgically after diagnosis of SMDP [24]. In the second report this concerned a patient with metastasized disease who was also treated surgically immediately after diagnosis of SMDP [16]. In both cases, despite early surgical intervention, the patients died due to ongoing abdominal infection and respiratory failure.

We did not perform endoscopic nasobiliary drainage (ENBD) routinely in patients with SMDP for several reasons: in all cases endoscopic closure of the perforation was attempted and, after apparent successful closure, this was confirmed with the administration of intraluminal contrast. Adding ENBD to endoscopic therapy was not considered to be of added value. In those patients with persistent leakage, usually confirmed via percutaneous drainage, the added value of ENBD was considered to be very limited. Lastly, the role of ENBD in our unit is, contrary to for example Asian clinical practice, very limited and typically used for patients with refractory biliary leakage after surgical procedures or trauma. The most important risk factor for SMDP in our study was the indication for biliary drainage of a perihilar stricture. All perforations occurred in patients with a perihilar stricture after the placement of a plastic stent $\geq$ $12 \mathrm{~cm}$ in length. These findings are in line with other reports [4, $5,8,13,17,23-25,27-29]$. Only two case reports were published in which a perforation was reported with shorter stents [9-15]. Longer stent length was also associated with a higher risk of SMDP at univariate regression analysis. Another potential risk factor that we identified with univariate regression analysis was when a stent was placed to drain the left liver lobe. However, this finding should be interpreted with caution as the model was of risk of multiple testing due to the relatively low number of cases and the high number of possible risk factors tested, potentially resulting in a false-positive association (type I error).

Nevertheless, the fact that stents placed into the left biliary system seem to migrate more often compared to those placed in the right biliary system could be argued as this might be the resultant of the sharper anatomical angel and more bended position of a left sided intrahepatic stent which provokes the stent to straighten due to material rigidity thereby causing outward migration. And migration of stents deployed in the left intrahepatic ducts was also described in previously published case reports $[25,27,29]$.

A potential solution to decrease the rate of SMDP is changing the type of stents used for drainage. In our series, all SMDPs occurred with straight plastic stents. During the study period we switched from placing straight stents with a center bend to straight stents with a duodenal bend with the hypothesis that this would decrease the risk of migration and thereby SMDP. However, our results show that SMDP occurred equally with both type of stents. The use of single or double pigtail stents could be an alternative for straight plastic stents, as they are less traumatic at its distal and/or proximal tip. However, their use for drainage of perihilar strictures is hampered by the lack of pushability to position the stents adequately across the stricture and therefore single or double pigtail stents were not used for drainage of perihilar strictures our patients. With regard to the diameter of the stents, it could be suggested to place $7 \mathrm{Fr}$ stents instead of $10 \mathrm{Fr}$ stents, as the former are more flexible with possibly less risk of SMDP. In our study, SMDP occurred with both $7 \mathrm{Fr}$ stents and $10 \mathrm{Fr}$ stents, but only three patients had one or multiple $7 \mathrm{Fr}$ stents in situ. Even though stent diameter was not statistically significant at univariate analysis, suggesting that a larger stent diameter does not increase the risk of SMDP, placement of one or multiple smaller diameter stents could still be considered, as type II statistical errors are possible with these low numbers of cases.

The use of SEMS could be a promising alternative. So far, uncovered SEMS are widely used but only in patients with an irresectable malignant (hilar) stricture. However, Grünhagen et al. already showed that pre-operative deployment of an uncovered SEMS in patients with resectable hilar CCA is feasible and provides adequate biliary drainage, without the need for re-intervention and without a negative effect on surgery [33]. The use of covered SEMS is not recommended in irresectable hilar CCA due to the risk of occlusion of the side braches of the intrahepatic ducts [34]. However, covered SEMS are of lower risk for recurrent biliary obstruction due to tumor ingrowth. A review ar- 
ticle by Naitoh et al. reported a shorter time to recurrent biliary obstruction with covered SEMS as compared to uncovered SEMS, but with a success rate of $100 \%$ for re-intervention when using fully covered SEMS (FCSEMS) [35]. And therefore, an interesting alternative for placement of plastic stents in patients with irresectable CCA could be placement of a FCSEMS to drain the left liver lobe and placement of a plastic stent to drain the right liver lobe. Although a few case reports have been published on SMDP after insertion of a SEMS [6, 10, 15, 20,24], in the majority of the cases the migrated stent was a covered SEMS [15, 20,24]. Prospective studies are needed to investigate the safety and (cost-) effectiveness of use of uncovered SEMS in patients with hilar duct strictures that are potential candidates for surgery.

To our knowledge, this is currently the largest cohort study to report on SMDP and its prevalence rate. Due to our prospectively collected complication registry, and manual review of all (>2400) endoscopy reports and radiological images, no cases of SMDP were missed. Therefore, this study for the first time provides a reliable estimate of the rate of SMDP after biliary plastic stent placement. However, some limitations of our study warrant consideration. First, as this study was a retrospective study, not all potential confounding factors could be accounted for. However, all medical records were screened for predefined items to facilitate a detailed and complete data collection. Second, due to the low number of cases and the number of examined risk factors we might have increased the risk of false-positive results (type I error), and were not able to perform a multivariate analysis. A larger cohort study with more SMDPs cases should be conducted to be able to more reliably test for associations between possible risk factors and the occurrence of SMDP.

\section{Conclusion}

In conclusion, this is the first study to report on the prevalence rate of SMDP in patients who undergo ERC. Despite the overall low risk of SMDP, it represents a noteworthy and clinically relevant potentially life-threatening complication of ERC after transpapillary drainage for perihilar biliary strictures. The risk of SMDP in patients referred for this indication needs to be acknowledged. In symptomatic patients after ERC for drainage of a perihilar stricture clinicians should have a high clinical suspicion for this complication. Future studies should focus on differential means of biliary drainage for perihilar biliary stenosis to prevent the occurrence of SMDP including a more frequent use of metal stents.

\section{Competing interests}

Dr. Poley is a consultant for and receives speaker's fees and travel expenses from Boston Scientific, Cook Medical, and Pentax Medical. Prof. Bruno is a consultant and receives support for industry and investigator-initiated studies from Boston Scientific, Cook Medical, and Pentax Medical, and support for investigator-initiated studies from Mylan, ChiRoStim, and $3 \mathrm{M}$.

\section{References}

[1] Dumonceau JM, Tringali A, Papanikolaou IS et al. Endoscopic biliary stenting: indications, choice of stents, and results: European Society of Gastrointestinal Endoscopy (ESGE) Clinical Guideline - Updated October 2017. Endoscopy 2018; 50: 910-930

[2] Anderson MA, Appalaneni V et al. American Society for Gastrointestinal Endoscopy Standards of Practice $C$. The role of endoscopy in the evaluation and treatment of patients with biliary neoplasia. Gastrointest Endosc 2013; 77: 167-174

[3] Moy BT, Birk JW. An update to hepatobiliary stents. J Clin Transl Hepatol 2015; 3: 67-77

[4] Coppola R, Masetti R, Riccioni ME et al. Early retroduodenal perforation following endoscopic internal biliary drainage. Endoscopy 1993; 25: $255-256$

[5] Humar A, Barron PT, Sekar AS et al. Pancreatitis and duodenal perforation as complications of an endoscopically placed biliary stent. Gastrointest Endosc 1994; 40: 365-366

[6] Marano BJ Jr, Bonanno CA. Metallic biliary endoprosthesis causing duodenal perforation and acute upper gastrointestinal bleeding. Gastrointest Endosc 1994; 40: 257-258

[7] Bui BT, Oliva VL, Ghattas G et al. Percutaneous removal of a biliary stent after acute spontaneous duodenal perforation. Cardiovasc Intervent Radiol 1995; 18: 200-202

[8] Roses LL, Ramirez AG, Seco AL et al. Clip closure of a duodenal perforation secondary to a biliary stent. Gastrointest Endosc 2000; 51: 487-489

[9] Novacek G, Hormann M, Puig S et al. Duodenal perforation secondary to placement of a biliary endoprosthesis diagnosed by multislice computed tomography. Endoscopy 2002; 34: 351

[10] Miller G, Yim D, Macari M et al. Retroperitoneal perforation of the duodenum from biliary stent erosion. Curr Surg 2005; 62: 512-515

[11] Paikos D, Gatopoulou A, Moschos J et al. Migrated biliary stent predisposing to fatal ERCP-related perforation of the duodenum. J Gastrointestin Liver Dis 2006; 15: 387-388

[12] Fatima J, Baron TH, Topazian MD et al. Pancreaticobiliary and duodenal perforations after periampullary endoscopic procedures: diagnosis and management. Arch Surg 2007; 142: 448-454 ; discussion 454445

[13] Bharathi RS, Rao PP, Ghosh K. Intra-peritoneal duodenal perforation caused by delayed migration of endobiliary stent: a case report. Int Surg 2008; 6: 478-480

[14] Hsu YC, Wu YM, Wang HP. Education of imaging. Hepatobiliary and pancreatic: biliary stent causing imminent duodenal perforation. Gastroenterol Hepatol 2008; 23: 817

[15] Lee TH, Park DH, Park JY et al. Aortoduodenal fistula and aortic aneurysm secondary to biliary stent-induced retroperitoneal perforation. World Journal of Gastroenterology 2008; 14: 3095-3097

[16] Lo CH, Chung S, Bohmer RD. A devastating complication: duodenal perforation due to biliary stent migration. Surg Laparosc Endosc Percutan Tech 2008; 18: 608-610

[17] Yaprak M, Mesci A, Colak T et al. Biliary stent migration with duodenal perforation. Eurasian J Med 2008; 40: 154-156

[18] Zeb F, Kevans D, Muir K et al. Duodenal impaction/perforation of a biliary stent-a rare complication in the management of choledocholithiasis. J Gastrointestin Liver Dis 2009; 18: 391-392

[19] Lin H, Li ZS, Zhan XB. Asymptomatic duodenal perforation from obstructed and migrated biliary stent. Endoscopy 2011; 43: (Suppl. 02): E40-41

[20] Siddiqui AA, Mehendiratta V, Loren D et al. Fully covered self-expandable metal stents are effective and safe to treat distal malignant 
biliary strictures, irrespective of surgical resectability status ] Clin Gastroenterol 2011; 45: 824-827

[21] Prachayakul V, Aswakul P, Kachintorn U. Duodenal perforation due to plastic stent migration successfully treated by endoscopy. Gastrointest Endosc 2012; 75: 1265-1266

[22] Smart P, Keenan D, Campbell W et al. Duodenal perforation secondary to migration of endobiliary prosthesis. BMJ Case Rep 2012: doi:10.1136/bcr-2012-006711

[23] Issa H, Nahawi M, Bseiso B et al. Migration of a biliary stent causing duodenal perforation and biliary peritonitis. World J Gastrointest Endosc 2013; 5: 523-526

[24] El Zein MH, Kumbhari V, Tieu A et al. Duodenal perforation as a consequence of biliary stent migration can occur regardless of stent type or duration. Endoscopy 2014; 46 : (Suppl. 01): E281-282

[25] Kusters PJ, Keulen ET, Peters FP. Duodenal perforation following bile duct endoprosthesis placement. Endoscopy 2014; 46 : (Suppl. 01): E646-647

[26] Kriss M, Yen R, Fukami N et al. Duodenal perforation secondary to migrated biliary stent in a liver transplant patient: successful endoscopic closure with an over-the-scope clip. Gastrointest Endosc 2015; 81: 1258-1259

[27] Barakat MT, Kothari S, Banerjee S. Cut and Paste: endoscopic management of a perforating biliary stent utilizing scissors and clips. Dig Dis Sci 2018; 63: 2202-2205

[28] Ferm S, Fisher C, Hassam A et al. Primary endoscopic closure of duodenal perforation secondary to biliary stent migration: a case report and review of the literature. J Investig Med High Impact Case Rep 2018; 6: doi:10.1177/2324709618792031

[29] Ekmektzoglou K, Nikou E, Apostolopoulos P et al. Size does matter: when a large plastic biliary stent ends up in the root of the mesentery. Clinical Journal of Gastroenterology 2019; 12: 102-105

[30] Kim SH, Moon JH, Lee YN et al. Endoscopic management of duodenal perforations caused by migrated biliary plastic stents. Endosc Int Open 2019; 7: E792-E795

[31] Saranga Bharathi R, Rao P, Ghosh K. latrogenic duodenal perforations caused by endoscopic biliary stenting and stent migration: an update. Endoscopy 2006; 38: 1271-1274

[32] Dumonceau JM, Kapral C, Aabakken L et al. ERCP-related adverse events: European Society of Gastrointestinal Endoscopy (ESGE) Guideline. Endoscopy 2020; 52: 127-149

[33] Grunhagen DJ, Dunne DF, Sturgess RP et al. Metal stents: a bridge to surgery in hilar cholangiocarcinoma. HPB (Oxford) 2013; 15: 372378

[34] Dumonceau JM, Tringali A, Papanikolaou IS et al. Endoscopic biliary stenting: indications, choice of stents, and results: European Society of Gastrointestinal Endoscopy (ESGE) Clinical Guideline - Updated October 2017. Endoscopy 2018; 50: 910-930

[35] Naitoh I, Inoue T, Hayashi K. Which is better for unresectable malignant hilar biliary obstruction: Side-by-side versus stent-in-stent? Int ] Gastrointest Interv 2018; 7: 78-84 